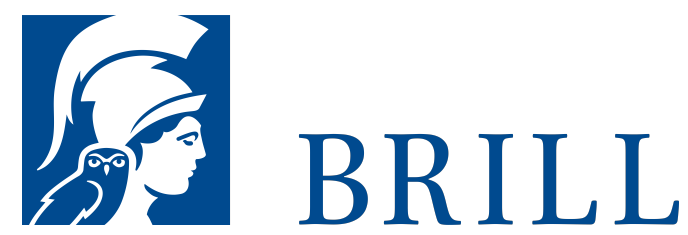

\title{
Die "innere" Landesgründung Nordrhein-Westfalens
}

Konflikte zwischen Staat und Selbstverwaltung um den Aufbau des Bundeslandes (1945-1953)

Author: Ansgar Weißer

»Formal « wurde das Land Nordrhein-Westfalen am 23. August 1946 gegründet. Die Entscheidung für den Zusammenschluss der nördlichen Rheinprovinz und der Provinz Westfalen hatte allerdings weder die Bevölkerung noch die Politik, sondern die britische Besatzungsmacht getroffen. Erst nach der Gründung Nordrhein-Westfalens stellte sich die Frage nach dem Staatsund Verwaltungsaufbau.

Von besonderer Bedeutung für die »innere Landesgründung « war die Neudefinition des Verhältnisses von Staat und kommunaler Selbstverwaltung. Die vorliegende Untersuchung rückt die politischen Konflikte zwischen den Vertretern beider Ebenen um die Verteilung von Aufgaben und Kompetenzen in den Mittelpunkt. Detailreich stellt sie u.a. die gescheiterten Bemühungen um eine Beteiligung von Kommunalvertretern an der Gesetzgebung dar.

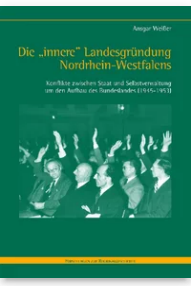

Pages: XII + 819

Seiten

Language:

German

Subjects: Global

History, History

Publisher: Brill |

Schöningh

Series:

Forschungen zur

Regionalgeschichte,

Volume: 68

E-Book (PDF)

Released online:

3o Dec 2019

ISBN: 978-3-

657-77331-2

List price

USD \$111.0o

Hardback

Publication date:

11 Jun 2012

ISBN: 978-3-

5०6-77331-9 
Ansgar Weißer, geb. 1970, ist promovierter Historiker; er war nach seinem Studium der Geschichte und Germanistik in Münster am LWL-Institut für westfälische Regionalgeschichte und als Lehrbeauftragter an den Universitäten Münster und Düsseldorf tätig. Zurzeit Lehramtsanwärter am Studienseminar Rheine.

For more information see brill.com

Order information: Order online at brill.com +44330 3330049 | customerservices@brill.com Submission information: brill.com/authors

Titles published by Brill | Fink, Brill | mentis or Brill | Schöningh: +49(o)715413279216| brill@brocom.de 